\section{Fractals in the Classroom}

In writing this column, my slant is different from that of previous contributors. I am not a volunteer in the classroom, but a consultant on National Science Foundation (NSF) grants aimed at bringing modern science into the high school classroom. The teams I work with are engaged in research on how to change U.S. science education. One primary goal is to investigate how best to introduce "advanced technology," i.e., computers, into the classroom. Nevertheless, lessons I have learned should prove valuable to scientists engaged in other outreach programs.

My training is as a theoretical condensed matter physicist. While a postdoctoral fellow, I organized undergraduate experimental research projects in my field of interest, which is far-from-equilibrium growth. Research experiments in this field can still be done inexpensively, and without great technical overhead. When the research money dried up, I found employment with education projects funded by NSF's Applications of Advanced Technology Program. One project at Boston University (Prof. H.E. Stanley was the principal investigator), entitled On Growth and Form, is precisely in my field of expertise. The experiences I share below are from this project.

My principal task is the design of inexpensive experiments to demonstrate interesting pattern formation processes. The experiments are intended to provide students with a hands-on experience prior to investigating the underlying physics with computer simulations. Among the experiments are electrochemical deposition and viscous fingering. We also use more standard experiments such as Liesegang ring formation and crystallization from supersaturated solution. Since our mandate is to develop interdisciplinary connections, our laboratory has developed experiments to study bacterial colony morphology, termite foraging patterns, and plant root growth.

Discovering the central role, and isolation, of the high school teacher easily ranks as my most important experience. I have been lucky to work with some very gifted teachers. Most of them are from suburban school systems. Nevertheless, these teachers are isolated. They are isolated from the scientific community, from technological advances, and even from colleagues. Their day begins at 7:00 a.m. in school and runs until 4 or 5 in the afternoon; during this period they are lucky to have time for lunch. Everything is done in a hurry. There is little time for reflection. Teachers are isolated from the simplest requirement for scientific enrichment-free time.

The need for a national focus on retraining teachers rather than students is obvious: If we change the way one teacher teaches, this affects roughly 100 students per year every year over the teacher's career. And teachers affect their colleagues. The chain reaction is obvious.

What have I learned about designing experiments for the classroom? Perhaps the first is to avoid "gee whiz" experiments performed as demos by the teacher, or even as stand-alone activities by the students. There are dozens of neat and exciting experiments that can knock the socks off students. But having done so, what was accomplished? What did the students learn? What did the teacher learn? Will the students be able to transfer their new knowledge to a different problem? Do the students have a quantitative sense of what happened?

To be concrete, I will describe the development of our electrochemical deposition experiment. This may appear to be an odd experiment to bring to high school students. In part, we were motivated to adopt it by our mandate-to bring modern research still pursued by research scientists to high schools. For a number of years, I have done research on the patterns formed by electrodeposits. I know that at its simplest, this is a cheap and easy experiment. One needs two plates of plexiglass with a hole in the center for the cathode, an anode surrounding it, an electrolytic solution between these terminals, clamps for the plates, and a power supply. When a potential difference is applied between the cathode and anode, and a salt such as copper sulfate is the electrolyte, a deposit grows on the cathode. The deposit's pattern is a

The Education Exchange highlights the experiences of scientists and engineers with local schools, along with helpful hints and resources. If you would like to share your own involvement in science education, contact: Finley Shapiro, Department of Electrical and Computer Engineering, Drexel University, Philadelphia, PA 19104, U.S.A. Phone (215) 895-6749; fax (215) 895-1695; e-mail: shapiro@ece.drexel.edu function of the electrolyte molarity, the applied voltage, and species of ion deposited. The result is a rich experiment for a student to explore.

But what can the student do with this experiment? Gee whiz, pretty patterns! And in the first class to do the experiment, that was how the students responded. The experiment did not stand alone; it was part of a curriculum piece which included a computer simulation of the growth of a deposit. But the students didn't really make the connection.

In the second year the students used a scanner to grab the image of the aggregate. This image could then be analyzed using a program developed by our project, or with public domain software. Specifically, the students were able to measure the fractal dimensions of their deposits. (Fractals are part of our curriculum and are familiar to the students.) The experiment was now quantitative with three different measures of the fractal dimension. Students accumulated current, radius, and time interval data during the deposit growth, and they estimated the dimension by analyzing this data. They measured the dimension directly with the image analysis software. They also measured the dimension of their simulated aggregates, using the same image analysis software, to compare with their experimental results. Now we were beyond gee whiz. There were experimental anomalies to account for (Why did the image dimension differ from that computed from the mass versus the radius?), and systematics as a function of parameters to investigate (Increase the voltage and what happens to the dimension? What is the difference between copper and zinc? What happens as a function of molarity?), and there were hypotheses to be checked by computer simulation.

The word I learned from this was investment. If the students are invested in a project it becomes their activity, not the teacher's. A quantitative handle on the experiment is critical. It justifies the students' investment by providing avenues for exploration. The more students are involved in an experiment from the ground up (mixing solutions, designing), the greater their investment. Students love to build things. In another unit the students measure the resistance of a fractal resistor network. Classes quickly become engaged in building as large a network as feasible.

When possible, students should be given the freedom to determine what to investigate. This is a tough step for teachers to take since it involves some loss of 
control. But have confidence! If the students are properly prepared, their creativity and curiosity will produce ideas which they must otherwise be force fed.

So far I have stressed helping teachers and developing student investment. I would like to add to this another goal. If possible, when you visit the classroom, involve a colleague who is a woman or a minority group member. The best is a young person-a graduate student or a young professional - to give students the sense that not all scientists are nerds.

If I could wish for a change in education, my first target would be to end the isolation of teachers. Would it be possible to form an alliance among universities, industry laboratories, and high schools, between researchers and teachers, in which researchers periodically teach in high schools? And let high school teachers take research sabbaticals? High school teachers are physicists, chemists, biologists, geologists, and mathematicians too. Many come from a research or engineering background. The feasibility of this proposal is limited not by the research ability of high school science teachers, but by the teaching skills of research scientists.

\section{Acknowledgments}

The team involved in the project described here is a collaboration of research scientists and education research specialists. There is not space for me to thank everyone from whom I have learned. At Boston University I work with Kenneth Brecher, $H$. Eugene Stanley, Edwin Taylor, and Paul Trunfio on the physics side; on the education side are Gerald Abegg, Richard Audet, Melissa Ferris, Mary Shann, and Linda Shore; in the schools I have learned about teaching from Paul Hickman, Charles Hurwitz, Joseph Jordan, and Dennis McCowan. I would also like to thank the graduate students and postdoctoral researchers in the Center for Polymer Studies, and the legion of undergraduates who are our programmers and laboratory assistants.

PETER GARIK

Peter Garik is a research associate in the Department of Physics, Boston University and an educational consultant. His prime educational goal is to determine how to get high school students to pursue a project after the bell rings.

To receive additional information on how you can get involved in enhancing $\mathrm{K}-12$ science education, circle number 120 on the Reader Service Card.

\section{LVMH - MOET HENNESSY LOUIS VUITTON CALLS FOR APPLICATIONS FOR THE 1994 SCIENCE FOR ART PRIZE}

The theme of the "Science for Art" Prize this year stresses the unpredictable aspects in the behavior of matter and its manifestations, on all theoretical or experimental levels.

Two prizes, each worth FF 100,000 (equivalent to about US $\$ 18,000$ ) will be awarded:

- A SCIENTIFIC PRIZE, for the scientific study offering the largest field of investigation of fundamental or applied research.

- An INNOVATIVE PRIZE, for the most promising applied research with a technological or commercial value.

The Prize recipients will be invited by LVMH Moet Hennessy Louis Vuitton to the Award Ceremony in Paris, France, in July 1994 to receive their prize and a commissioned work of art.

Other submissions considered of high international level by the Scientific Jury will be rewarded with the VINCI OF EXCELLENCE, a hand-assembled metal dodecahedron based on an original drawing by Leonardo Da Vinci.

Submissions must be postmarked by January 29, 1994

For rules and application forms, contact: Olivier J. Goniak

LVMH Moet Hennessy Louis Vuitton, Inc

Two Park Avenue, Suite 1830, New York, NY 10015

Tel: (212) 340-4789, Fax: (212) 340-7620

\section{"ULTRA THIN"}

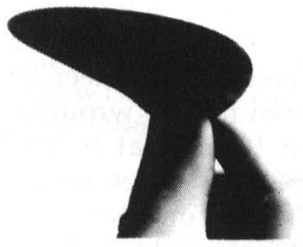

2-4 $\mu$ THIN

\section{silicon membranes!}

\section{Available in 2 and 3 "}

diameters, these double side polished elastic membranes combine a balance of thinness, parallelism and flatness heretofore not available in single crystal silicon.

\section{Applications include: -micromachining -X-ray lithography -particle beam focusing - stress diaphragms -bonded silicon}

\section{All processing from crystal} growth to polishing, is done on VSI premises.

Whether your requirements are in research or production quantities, let's talk about putting these membranes to work for you.

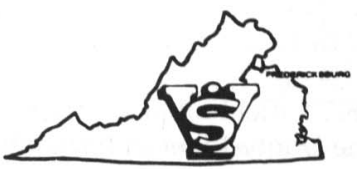

VIRGINIA SEMICONDUCTOR, INC.

1501 Powhatan Street Frederickburg, VA 22401

Phone (703) 373-2900

Telex 9102506565

Fax (703) 371-0371 